\title{
The Presence of Fasciola hepatica (Liver-fluke) in Humans and Cattle from a 4,500 Year Old Archaeological Site in the Saale- Unstrut Valley, Germany
}

\author{
K Dittmar ${ }^{+}$, WR Teegen* \\ Department of Zoology, Brigham Young University, Provo, Utah, USA *Institute of Prehistory, University of Leipzig, Leipzig, \\ Germany
}

During an excavation of a site of the corded ware culture in the Saale-Unstrut-Valley (ca. 3000 BC) in Germany, a soil sample from the pelvis of a human skeleton was studied under palaeoparasitological aspects. Eggs of the trematode Fasciola hepatica and of the nematode genus Capillaria were found.

This is the first case of a direct association of a F. hepatica-infestation to both a prehistoric human skeleton and domesticated animal remains. Sheep and cattle bones were present at the same site and $\mathrm{F}$. hepatica eggs were found in bovine samples. This strongly points toward an existing infection cycle, involving humans as a final host.

Key words: paleoparasitology - Fasciola hepatica - human - cattle - late Neolithic - Germany

Most studies regarding paleoparasitological surveys refer to eggs of whipworms, pinworms, taeniid tapeworms, hymenolepidid tapeworms and Ascaris roundworms. They have been found in latrine sediments, coprolites and mummy intestines (Araujo et al. 2000). Liver fluke eggs, however, are very rarely reported in prehistoric fecal material. All current reports are from European material. Szidat (1944) found Fasciola eggs in bog bodies from Eastern Germany. In the material from the prehistoric coastal settlement Feddersen Wierde (Northern Germany) both eggs of the liver fluke and shells of Lymnea truncatula were found (Szidat 1944). Furthermore, according to botanical analyses, a liver fluke vegetation type was present at the site.

Also, in a Viking age site at Ribe (Denmark) F. hepatica was found, together with eggs of other intestinal worms. In two cases from the North Sea shore, the liver fluke probably came from sheep feces (Nansen \& Joergensen 1977).

This paper describes the first report of $F$. hepatica eggs from both human and cattle remains from the same archeological site. The remains are dated into the same time period. An ongoing infection cycle involving human and animal hosts is thought to be highly probable.

\section{MATERIALS AND METHODS}

Sample collection - Between 1996 and 1999 a largescale-excavation was carried out at Karsdorf in Southern Saxony Anhalt, Germany. It is a multiperiod site (middle Neolithic to Roman Iron Age, approximately 3500 BC to 200 AD). The site is called Karsdorf 9 and is located on a southern slope of the river Unstrut. In the excavation area

\footnotetext{
${ }^{+}$Corresponding author. Fax: +1-801-422.0090

E-mail: katharinad@ hotmail.com

Received 26 August 2002

Accepted 25 November 2002
}

an extended cemetery was discovered. Specific findings are dating most of the graves into the late Neolithic - or copper age - Corded Ware Culture to the middle of the third millenium BC.

The cemetery is composed of nearly 50 burial chambers and is one of the largest of its time in central Germany. More than 70 human individuals are buried there, several animal skeletons such as horses and cattle have been found. Burial chamber 2229 contained 6 human individuals, mostly West-East oriented. Burial number 2001 contained a cow skeleton.

Rehydration - Soil samples of $500 \mathrm{~g}$ were taken from the pelvic region of one of the human skeletons as well as from the cow burial. The samples were taken directly from the bowl formed by the inclination of the sacrum (see Reinhard et al. 1992 for details). For each burial a negative control from the surroundings of the burial was examined. Fifteen samples, each weighing $5 \mathrm{~g}$ were prepared from the $500 \mathrm{~g}$ of original sample. Each unit was screened through a fine mesh, the screened samples were rehydrated in $200 \mathrm{ml} 0.5 \%$ trisodium-phosphate solution in the refrigerator (2 weeks). Occasional stirring was applied and 5 Lycopodium spore tablets (containing 13,911 spores/ tablet) were added to each sample (Stockmarr 1971).

After 2 weeks the samples were washed in distilled water. Hydrochloric acid $(10 \mathrm{ml})$ was added to dissolve calcium carbonate. The material was then transferred to a sedimentation funnel to separate the specific heavier material from the lighter material. The lighter material could be found on top of the settled sand. It was removed by a wide gauge pipette and used for further processing. The process was followed by a flotation with sodium chloride (specific gravity 1.2). The upper portion of the solution was carefully removed with a pipette and subsequently centrifuged twice at $1500 \mathrm{rpm}$ for $3 \mathrm{~min}$. Three drops of the remaining sediment were mounted in a Berlese fluid, commonly used in entomology (Disney \& Henshaw 1988).

Considering a relatively even distribution of the $\mathrm{Lyco}$ podium spores in the solution, the mean egg index (MEI) per milliliter was calculated as follows: 


$$
\mathrm{MEI} / \mathrm{ml}=\frac{\mathrm{n}_{\mathrm{e}} \times \mathrm{SP}_{\mathrm{t}}}{\mathrm{n}_{\mathrm{s}} \times \mathrm{SRI}_{\mathrm{XV}}}
$$

MEI: mean egg index; $\mathrm{n}_{\mathrm{e}}$ : total number of eggs counted; $\mathrm{SP}_{\mathrm{t}}$ : spores per Lycopodium-tablet; $\mathrm{n}_{\mathrm{s}}$ : total number of samples (slides); SRI: spore reference index; $\mathrm{V}_{\mathrm{t}}$ : initial sample volume.

The SRI (spore reference index) was 200 Lycopodium spores per slide, the total number of slides counted was 125 for each sample.

The specification of the eggs took place at the Parasitological Laboratory of the Veterinary Faculty of Leipzig, based on current morphological keys (Ash \& Orihel 1988).

\section{RESULTS AND DISCUSSION}

In 9 of the 15 human samples eggs of $F$. hepatica (Fig. 1) could be detected and in two of them eggs of Capillaria sp. (Fig. 2). Three of the 15 bovine samples contained $F$. hepatica eggs, in all of them Capillaria sp. eggs were prevalent.

Two important questions were asked at this point of the investigation. Are the findings related to a true infection of this particular human individual or are they due to a contamination? To answer these questions, the life cycle

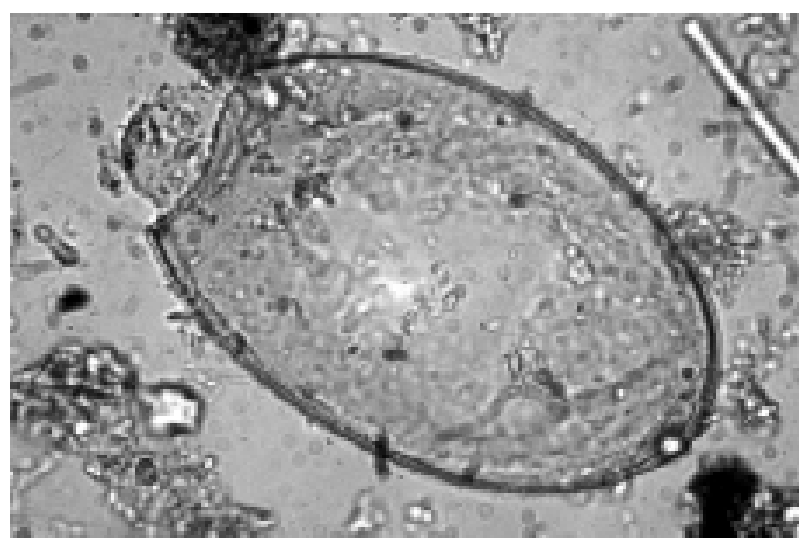

Fig. 1: hatched egg of Fasciola hepatica from a soil sample of the pelvic region of a 4,500 year old skeleton.

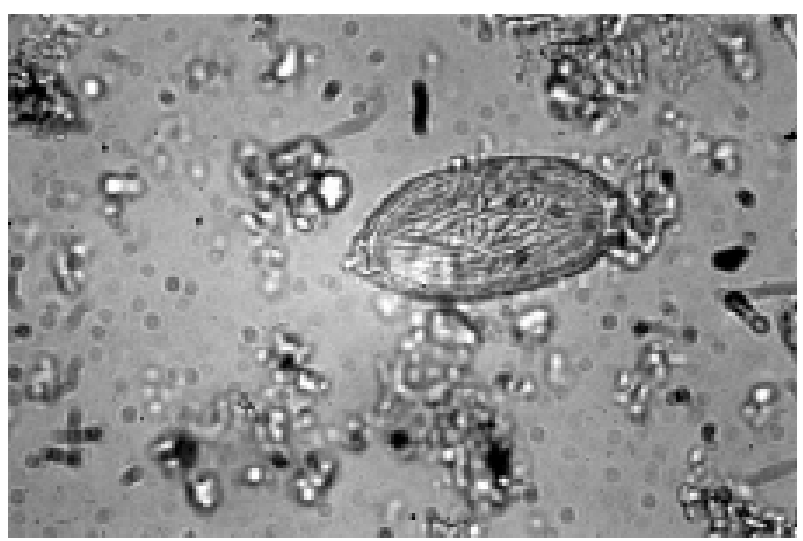

Fig. 2: egg of Capillaria sp. from a soil sample of the pelvic region of a 4,500 year old skeleton. as well as the preferred hosts of the parasites have to be considered.

F. hepatica is a trematode, the common liver fluke of sheep and cattle. Other ruminants and humans can be an additional, although not preferred host. The adults live in the bile ducts, where the eggs are laid. They pass on to the small intestine and are eventually excreted with the feces. This parasite requires an intermediate host, usually the cosmopolitan lymneaid snail Lymnea (Galba) truncatula. Shells of Lymnea sp. were found on the excavation site. Dating of the shells remained unclear. However, the presence of the snails suggest the ecological potential for the presence of this internal parasite. Humans mainly get infected by eating watercress (Nasturtium officinale) and so ingesting the encysted metacercariae sitting on the leaves. Ironically, watercress was eaten to cure upper abdominal pains, and has been used for a long time as a medicine or food (Schaffner 1999).

The fact, that the skeletons came from a grave, thus located considerably under the normal soil level, make a recent contamination possible only if rodents are involved. However, rodents nearly never get infected with this trematode. A second control, taken out from a side area of the same grave revealed no eggs of this internal parasite. The findings of the remains of the intermediate host (Lymnea sp.) in the surroundings, as well as the presence of sheep and cattle bones, and subsequently the finding of $F$. hepatica in the bovine samples make an infection cycle highly possible.

The MEI of $F$. hepatica for the human sample was 0.1 , for the bovine sample 0.04. A true prevalence of a parasite in an archeological sample can not be established (Reinhard et al. 1988). Diagenetic factors result in the destruction of biological evidence, therefore the MEI is only an estimation of a potential value and should be interpreted with care. Although the numerical value of the MEI for F. hepatica seems to be relatively low, it actually indicates the potential presence of 20 eggs per $15 \mathrm{~g}$ soil, which is a high value for an archaeological sample. This strengthens the hypothesis of a true infestation, as a later contamination is unlikely to result in those high numbers.

This parasite has relatively high pathological significance. In cattle and small ruminants the pathogenesis is partly attributable to the invasive stages in the liver and the blood feeding in the bile ducts by the adults. Infected livers are unsuitable for human consumption, resulting in the loss of an important source of protein (Boch 2000).

In human the migration is accompanied by an intense inflammatory reaction with prominent eosinophils. The chronic form of the infection is more frequent. After long standing infections, health is seriously affected. Bile duct hyperplasia, pericholangitis, periportal fibrosis, and obstruction may be found (Boch 2000). The results make it likely, that the prehistoric Neolithic man was infected, although up to now, no direct relationship between a bovine and a human host could be established with archeological material.

The Capillaria egg findings are very likely due to rodents, who lived or passed by near the skeleton, and 
contaminated the area with their feces. A rodent (Clethrionomys spp.) and hamster (Cricetus cricetus) infecton of the site could be verified.

Only a total of 4 eggs were found in all samples.

Capillaria is among the species richest genera of nematodes. A majority of species affects rodents, the species typing is extremely difficult and was not done in this case. The findings of Capillaria-like eggs point towards a later provenience.

The majority of helminth infections are rarely fatal, but characteristically debilitating due to pathological changes provoked by the parasite. The pathology of helminth infections must always be considered in a broad framework, including physical damage, trauma and disruption caused by the parasite in situ, although in this case it is not possible to do so. The estimated life time of the individuals at this site ranges between 35 and 45 years. Further investigation towards pathological signs of helminth infections on the skeletons as well as sampling of more soil samples including ruminants has to be done.

Nevertheless there is sufficient proof to verify a true fasciolosis of this particular human individual with a very high probability.

\section{REFERENCES}

Araujo A, Reinhard K, Ferreira LF 2000. The role of mummy studies in paleoparasitology. Chungara 32: 111-117.

Ash LR, Orihel TC 1987. Parasites: a Guide to Laboratory Procedures and Identification, American Society of Clinical Pathologists, Chicago, p. 1-328.

Boch J 2000. Veterinärmedizinische Parasitologie, Blackwell Wissenschaftsverlag, Berlin, $730 \mathrm{pp}$.

Disney RHL, Henshaw DHC 1988. Berlese fluid for slidemounting insects. Antenna 12: 106-107.

Nansen P, Joergensen RJ 1977. Parasite eggs identified in material from archeological excavations in Ribe (Viking Age). Nordisk Vet Med 29: 263-266.

Reinhard K, Confalonieri UE, Herrmann B, Ferreira LF, Araujo A 1988. Recovery of parasite eggs from coprolites and latrines: aspects of paleoparasiological technique. Homo 37: 217- 239.

Reinhard K, Geib PR, Callahan MM, Hevly RH 1992. Discovery of colon contents in a skeletonized burial: soil sampling for dietary remains. J Archaeol Sci 19: 697-705.

Schaffner W 1999. Heilpflanzenkompendium. Vorkommen, Merkmale, Inhaltsstoffe, Anwendungen, Thalacker Verlag, Braunschweig, $678 \mathrm{pp}$.

Szidat L 1944. On the preservation of helminth eggs in preand early historical bog corpses. Ztschr f Parasitenk 13: 265-274.

Stockmarr J 1971. Tablets with spores used in absolute pollen analysis. Pollen et Spores 13: 615-621. 